\title{
UM PANORAMA SOBRE ECOSSISTEMA EMPREENDEDOR: O QUE A BASE SCOPUS TEM A NOS CONTAR?
}

Lucas Silvestre De Carvalho ${ }^{1}$

Silas Ferreira Reis De Oliveira ${ }^{1}$

Diogo De Siqueira Camargo Vasconcelos ${ }^{1}$

Edmundo Inácio Júnior ${ }^{2}$

\footnotetext{
${ }^{1}$ Universidade Estadual de Campinas (UNICAMP)

${ }^{2}$ Universidade Estadual de Campinas
} 


\section{UM PANORAMA SOBRE ECOSSISTEMA EMPREENDEDOR: O QUE A BASE SCOPUS TEM A NOS CONTAR?}

Resumo: O objetivo deste artigo é apresentar o panorama das publicações de pesquisas científicas sobre ecossistema empreendedor na base Scopus. Para tal o estudo buscou demonstrar os autores e artigos com maior número de publicações, principais redes de citação, principais autores referenciados por obras da temática, principais eixos de pesquisas sobre o tema por meio das palavras-chave utilizadas e principais revistas científicas que publicam sobre o tema. A metodologia aplicada foi pesquisa bibliométrica com a base Scopus como fonte de dados por meio da utilização do software VOSviewer ${ }^{\circledR}$. Como resultados da pesquisa foi demonstrado que a pesquisa de Teece (2007) é seminal para o embasamento teórico da área, apesar de não ser uma pesquisa que aborda a temática de ecossistemas empreendedores; a predominância de estudos sobre empreendedorismo universitário; a importância de três periódicos como principais disseminadores sobre a temática.

Palavras-chave: Ecossistema empreendedor. Empreendedorismo. Inovação. Empreendedorismo Universitário.

\section{$1 \quad$ Introdução}

Apesar da discussão sobre a importância das políticas regionais no desenvolvimento e ampliação da prática empreendedora ser algo comum desde meados dos anos 1970, estudos mais recentes demonstram que tais políticas não são o único fator que deve ser considerado para o fomento do empreendedorismo, considerando-se que tal prática é dependente de um sistema complexo que envolve diversos agentes (Stam, 2015).

A literatura traz algumas denominações bem próximas para este sistema complexo sendo chamados de "Ecossistemas Empreendedores", "Ecossistemas de empreendedorismo", "Ecossistemas de Inovação", entre outras formas de denominação, e estes ecossistemas empreendedores têm sido foco de novos estudos para auxiliar a compreensão do contexto do ambiente empreendedor (Nylund \& Cohen, 2017).

A fim de demonstrar o crescimento desta vertente de estudos, várias pesquisas foram observadas para tratar a temática deste artigo com destaque para as publicações de Spigel (2017), Nylund e Cohen (2017), Cohen (2006), Mack e Mayer (2016), Acs, Stam, Audretsch e O’Connor (2017), Audretsch e Belitski (2017), Anholon, Novaski, Pinto e Porto (2016), Shepard (2013), Stam (2015) e, Mas-Verdú, Ribeiro-Soriano e Roig-Tierno (2015).

A abordagem das pesquisas supracitadas demonstram itens relevantes acerca da formação de ecossistemas empreendedores, formação e desenvolvimento de locais propícios a para o desenvolvimento de empresas, como incubadoras de empresas e o papel do empreendedor dentro deste contexto.

Spigel (2017) apontou para uma defasagem de pesquisas relacionadas ao tema, enquanto Stam (2015) argumenta que a aproximação da academia a estudos relacionados ao tema apenas ocorreu com maior ênfase a partir do ano de 2010. Diante disso, optou-se por uma busca em 
uma das maiores bases de artigos científicos, a base Scopus, para demonstrar o cenário de publicações mundiais de pesquisas de Ecossistemas Empreendedores. A consulta fora feita apenas na Base Scopus pois, como mostrado por Archambault, Campbell, Gingras e Larivière (2009), a correlação entre as bases de dados Scopus e Web of Science é extremamente alta. Logo, não se justifica buscar em ambas para se ter resultados sobrepostos.

Por conseguinte, esta pesquisa tem como problema a seguinte questão: Como se caracteriza o panorama de publicações científicas sobre ecossistema empreendedor na base Scopus? A partir disto, o objetivo da pesquisa é apresentar o panorama das publicações de pesquisas científicas sobre ecossistema empreendedor na base Scopus. Sendo que, mais especificamente, a pesquisa buscará demonstrar quais são os autores com maior número de publicações diante da temática pesquisada, demonstrar as principais redes de citações e cocitações existentes entre os autores dos temas e países, apresentar os trabalhos mais relevantes, em termos de citações, para a formação dos conceitos sobre ecossistema empreendedor, apresentar os principais eixos de pesquisas sobre o tema, por meio da ocorrência de palavras-chave utilizadas pelos autores e apresentar as principais revistas científicas que publicam sobre o tema.

Um estudo como este justifica-se sob alguns aspectos. Spigel (2017) aponta que a pesquisa em ecossistemas está subdesenvolvida e sub-teorizada. Os ecossistemas representam um guarda-chuva conceitual abrangendo uma variedade de diferentes perspectivas sobre a geografia do empreendedorismo. Cabe ressaltar que os autores Nylund e Cohen (2017) e Spigel (2017) demonstram a existência de uma defasagem em estudos realizados na América do Norte e Europa.

Este trabalho justifica-se ainda como um passo anterior a construção de uma base conceitual sobre o tema pesquisado. Para tal base, é necessário antes desenvolver uma pesquisa que possa elencar os principais autores sobre o tema, principais trabalhos utilizados como base conceitual destes autores e, ainda, demonstrar onde a pesquisa está sendo desenvolvida com mais vigor, para demonstrar a comunidade acadêmica que se interessa pelo assunto onde buscar informações e parcerias científicas para o avanço de pesquisas relacionadas a esse tema.

\section{Ecossistemas empreendedores: contexto e definições}

O termo ecossistema empreendedor surge na literatura em meados dos anos 2000 concomitantemente ao debate sobre o desenvolvimento de capacidade dinâmica (Teece, 2007). Segundo esse autor, no âmbito de tal discussão teórica, o contexto ambiental ao qual a empresa está inserida, segundo o contexto de capacidade dinâmica, não limita-se ao ambiente da indústria e sim ao ecossistema de negócios considerando fornecedores, comunidade, instituições e indivíduos que impactam a atividade desenvolvida pela empresa. Tal discussão torna-se o estopim para diversos outros estudos que debruçam-se sobre o ecossistema empreendedor.

O empreendedorismo tratado como um sistema permite a ênfase nas interações entre os indivíduos e seus contextos institucionais, percepção essa que adota uma perspectiva ampla ao examinar indicadores individuais e nacionais da atividade empreendedora (Acs, Autio, \& Szerb, 2014). Conforme Spigel (2017), os ecossistemas empreendedores podem ser entendidos como um ambiente que suporta o empreendedorismo de inovação por meio da associação de fatores como cultura, redes sociais, investimentos e instituições. 
Ainda não haja uma definição comum para Ecossistemas Empreendedores Stam (2015), ao tratar sobre essa abordagem com base na literatura, menciona que o componente "ecossistemas" representa o conceito biológico da interação entre organismos vivos que, no caso do empreendedorismo, foca no contexto da relação social entre os atores que compõem o sistema. O termo "empreender" se refere à exploração de oportunidades para criação de novos negócios. Para Isenberg (2016), o ecossistema empreendedor representa um sistema socioeconômico auto organizado e autossustentável pela busca dos atores por seus interesses, em que há uma relativa independência de um controle central, porém políticas podem influenciar as estruturas de interação dos atores. O Quadro 1 traz algumas definições para a expressão ecossistema empreendedor:

\begin{tabular}{ll}
\hline Autor & Definição \\
\hline Ács et al. (2015) & $\begin{array}{l}\text { O ecossistema empreendedor refere-se a grande variedade de necessidades que um } \\
\text { novo empreendimento possui durante seu ciclo de vida inicial. }\end{array}$ \\
& $\begin{array}{l}\text { O ecossistema empreendedor refere-se ao contexto no qual o empreendimento está } \\
\text { inserido considerando a política, economia, cultura, apoio, capital humano e } \\
\text { Isenberg (2011) }\end{array}$ \\
Morris et al. (2015) & $\begin{array}{l}\text { O ecossistema de empreendedorismo refere-se ao contexto que fornece acesso a } \\
\text { financiamento, educação e transferência de P\&D, políticas e programas } \\
\text { governamentais, bem como infraestrutura física e profissional. }\end{array}$ \\
Singer et al. (2015) e & $\begin{array}{l}\text { Os ecossistemas de empreendedorismo incluem financiamento, políticas } \\
\text { governamentais, programas governamentais de empreendedorismo, educação para } \\
\text { o empreendedorismo, transferência de I\&D, infraestrutura comercial e legal, } \\
\text { abertura do mercado, infraestrutura física e normas culturais e sociais, que constitui } \\
\text { a base de nossa análise do ecossistema de empreendedorismo. }\end{array}$ \\
\hline
\end{tabular}

Figura 1 - Definições de ecossistema empreendedor.

Fonte: adaptado de Yan e Guan (2019, p. 626).

Nota-se que apesar do alinhamento entre alguns aspectos centrais da expressão ecossistema empreendedor, não existe uma definição consolidada sobre o assunto, bem como a definição de seus limites. Além disso, Isenberg (2016) evidencia que existem diversos erros na aplicação do termo ecossistema para este contexto. Tal erros são consequências de sua ampla utilização no campo do empreendedorismo e o distanciam de seu real significado. Os principais equívocos dizem respeito a possibilidade de criação ou controle do ecossistema, haja vista que os ecossistemas não podem ser criados. Além desses destaca-se também a imposição de limites geográficos a abrangência de um ecossistema empreendedor, considerando que a existência deste se limita ao espaço geográfico de uma região ou país e a inserção equivocada do empreendedor como o agente central de todo ecossistema.

Portanto, conforme defendem Roundy, Bradshaw \& Brockman (2018) os estudos sobre ecossistemas empreendedores seriam mais uteis se se focassem em identificar os componentes desse ecossistema para o estabelecimento de um entendimento mais amplo e profundo do funcionamento de ecossistema empreendedor de alto-nível.

Um estudo realizado com 70 cidades europeias sobre condições dos ecossistemas empreendedores nas cidades, propõem certas ações políticas para fomentar o empreendedorismo regional, entre elas destacando-se: reformar instituições formais para 
melhorar a dependência do apoio administrativo; parceria público-privada e alinhamento da tecnologia da informação com o ecossistema empreendedor; melhorar as instalações culturais; projetos educacionais destinados ao crescimento da cultura de empreendedorismo; estimular o acesso ao financiamento de indivíduos com maior capital humano em empreendedorismo (Audretsch \& Belitski, 2017). A administração do ecossistema significa a prática de gerenciar os benefícios elaborados pelo ecossistema que são chamados de "serviços ecossistêmicos", ou seja, a alocação de recursos para uso produtivo com maior possibilidade de obter os empreendimentos inovadores de altos retornos que impulsionam esse processo (Autio \& Levie, 2017; Seppelt, Dormann, Eppink, Lautenbach \& Schmidt, 2011).

Porém diversos autores argumentam que os estudos sobre ecossistemas empreendedores necessitam constatar a complexidade do fenômeno (Roundy et al., 2018; Spigel, 2017; Stam, 2015). Os ecossistemas empreendedores podem ser vistos como um sistema adaptativo complexo formado por componentes complexos (agentes e suas interações não lineares) em que as ações de um agente produzem adaptações ou modificações no ecossistema, surge por ações descoordenadas dos agentes individuais em que não há um agente que dirija as atividades do ecossistema e possui fronteiras abertas (porém com características geográficas e culturais) (Roundy et al., 2018).

\section{$3 \quad$ Metodologia}

Este trabalho foi desenvolvido utilizando a base de dados Scopus sem filtro de datas para que pudesse ser observado toda evolução de publicações sobre a temática, com vistas a verificar a estrutura de cooperação entre autores e instituições, os autores entrantes e as categorias de produção e continuidade, a regularidade de publicação e a distribuição de suas publicações ao longo do tempo.

As palavras-chave de busca foram "entrepren* AND ecosystem". Foram utilizados dois artifícios de busca como o asterisco (*) e o operador lógico (AND) que, respectivamente, são usados para buscar palavras derivadas daquele radical e restringir a busca combinada aos artigos que satisfaçam essas duas condições (palavras-chave).

Os resultados foram refinados a documentos do tipo "artigos", limitados as subáreas "negócios", "ciências sociais", "economia". Foram adicionadas as buscas as palavras "empreendedorismo", "ecossistemas", “inovação", "empreendedor" e "ecossistemas empreendedores". Após estes filtros, foram encontrados 377 artigos.

A justificativa para a escolha da base de dados supracitada leva em consideração a disponibilidade de acesso ofertada pela instituição de ensino a que os pesquisadores estão associados. Além disto, a escolha desta base de dados se deu pelo fato dela abranger um número significativo de periódicos, indexados pelos principais "publishers" da área acadêmica, tais como: Elsevier, Emerald, Springer, Inderscience Enterprises, IAEME Publication, Taylor and Francis Ltd., MDPI AG, Academic Press, Institute of Electrical and Electronics Engineers Inc., Prague Development Center, Brazilian Institute for Information in Science and Technology, Routledge, Econjournals, Medwell Journals, Academic Journals Inc., International Information Institute Ltd., John Wiley and Sons Ltd, IGI Global, Wiley-Blackwell, Mohammed Premier University, Italian Association of Chemical Engineering - AIDIC, Journal of Chemical and Pharmaceutical Research, Research India Publications. Ademais, o estudo de Maroufkhani, 
Wagner e Wan Ismail (2018) realizou uma revisão sistemática sobre a base Web Of Science, não contemplando a base Scopus, foco desta pesquisa.

Um processo de três estágios foi utilizado para esta revisão, modificado a partir de métodos empregados por Tranfiel, Denyer e Smart. (2003), Seuring e Müller (2008) e Igarashi, Boer e Fet (2013):

1. Coleta de material: o material a ser coletado é definido e delimitado.

2. Seleção de categoria: aspectos gerais, por exemplo, base de dados, ano de publicação, principais autores envolvidos, principais periódicos, entre outras informações relevantes.

3. Classificação e avaliação do material: o material é analisado de acordo com as categorias definidas no estágio 2.

Cabe ressaltar que este estudo se difere ainda da pesquisa realizada por Maroufkhani, Wagner e Wan Ismail (2018) que visou outros tipos de categorizações durante a revisão bibliográfica realizada.

Para a análise dos dados, foi observado o periódico no qual foi publicado, os autores e as instituições às quais eles se encontravam vinculados na ocasião da publicação. Além disto, analisou-se os principais países de origem dos trabalhos publicados. De posse dos artigos selecionados nessa primeira etapa, será efetuada a tabulação dos dados e efetuadas as análises buscando também identificar laços entre pesquisadores.

Os resultados serão apresentados de forma quantitativa, demonstrando o volume de artigos, de pesquisadores e de autorias presentes. Os aspectos analisados foram: a) quantidade de artigos publicados por autores e em quais periódicos; b) distribuição de pesquisadores segundo categorias de produção e de continuidade e coautorias relacionadas a cada categoria de produção e de continuidade; c) instituições de afiliação; d) autores e periódicos que publicaram sobre o tema.

É importante destacar que o software utilizado para fazer a categorização, VOSviewer ${ }^{\circledR}$, realiza a separação categórica da seguinte forma:

- Análise de coautoria: a relação do número de itens é determinada mediante ao número de documentos em coautoria. Esta categoria é subdivida entre autores e organizações a que estão vinculados;

- Análise de citação: a relação do número de itens é determinada mediante ao número de vezes em que cada autor citou outro autor. Esta categoria é subdividida em documentos (artigos), autores, fontes e organizações a que estão vinculados;

- Análise de conexões bibliográficas: o relacionamento entre os itens é baseado no número de referências que eles compartilham. Esta categoria, do mesmo modo que a anterior, é subdividida em documentos (artigos), autores, fontes e organizações a que estão vinculados e;

- Análise de cocitação: a relação entre os itens é determinada baseado no número de vezes que eles são citados juntos (que são coautores). Esta categoria é subdividida em referências citadas, autores citados e fontes citadas. 


\section{$4 \quad$ Apresentação e análise dos resultados}

Os resultados serão apresentados seguindo a seguinte ordem: artigos mais citados, autores mais citados, redes de coautoria, rede de autores referenciados, principais palavras-chave utilizadas na temática e, por fim, principais revistas científicas no meio.

Após a análise feita pelo software sobre os artigos mais citados entre todos os trabalhos de nossa base de dados sobre Ecossistemas Empreendedores, destaque o trabalho de Teece (2007), conforme pode ser visto na Figura 2.

\begin{tabular}{|c|c|c|c|}
\hline Autor & Artigo & Ano & Citações \\
\hline Teece, D. J. & $\begin{array}{l}\text { Explicating dynamic capabilities: the nature and microfoundations } \\
\text { of (sustainable) enterprise performance }\end{array}$ & 2007 & 3539 \\
\hline $\begin{array}{l}\text { Autio, E., Kenney, M., } \\
\text { Mustar, P., Siegel, D., } \\
\& \text { Wright, M. }\end{array}$ & Entrepreneurial innovation: The importance of context & 2014 & 274 \\
\hline Stam, E. & $\begin{array}{l}\text { Entrepreneurial Ecosystems and Regional Policy: A Sympathetic } \\
\text { Critique }\end{array}$ & 2015 & 217 \\
\hline Cohen, B. & Sustainable valley entrepreneurial ecosystems & 2006 & 151 \\
\hline Borges, M. et al. & $\begin{array}{l}\text { The open innovation research landscape: established perspectives } \\
\text { and emerging themes across different levels of analysis }\end{array}$ & 2017 & 141 \\
\hline
\end{tabular}

\section{Figura 2 - Artigos com maior número de citação.}

Fonte: elaboração própria.

Apesar de não ser uma pesquisa estritamente realizada sobre ecossistemas empreendedores, o autor aborda aspectos teóricos que dão embasamento à discussão sobre ecossistemas empreendedores, tais como o conceito explanado no estudo que empresas com fortes capacidades dinâmicas sustentam um desempenho superior em uma economia aberta não por se adaptar ao ecossistema, mas por moldar o meio através da inovação e colaboração com outras empresas e instituições. O autor denomina este contexto como Ecossistema de Negócios. Em seguida, como observado na Figura 2, os trabalhos de Autio (2014) e Stam (2015) aparecem logo em seguida. Em contraponto ao trabalho do Teece (2007) esses autores desenvolvem suas pesquisas na área de empreendedorismo.

Além da Figura 2, onde demonstram as quantidades de citações dos principais artigos da base de dados, é possível visualizar na Figura 3 as redes formadas pelos artigos com maior número de citações. 
Figura 3 - Rede de artigos com maior número de citação.

Fonte: elaboração própria.

O tamanho da circunferência de cada artigo representa a quantidade de citações, enquanto as conexões são determinadas pelo número de vezes que os documentos citam um ao outro. Dos 377 documentos que formam a base de dados, a rede da Figura 3 é formada por 204 artigos que estão interconectados. Destaca-se a importância de Stam (2015) para a formação da rede que, apesar de não ser o artigo mais citado da base de dados, é o documento com maior número de ligações com os outros arquivos da base (61 ligações). Já a pesquisa de Teece (2007), apesar de ser o artigo mais citado na base de dados, não possui forte ligação de citação com os outros documentos da base, ou seja, a pesquisa de Teece (2007) é citada pelos autores da área, mas essa pesquisa não citou os trabalhos sobre ecossistema empreendedores corroborando com o fato de ser um documento que dá embasamento à discussão sobre ecossistemas empreendedores, apesar de não ser uma pesquisa com essa temática.

Após apresentação dos trabalhos mais citados, são apresentados os autores mais citados resultantes desta pesquisa. Seguindo o primeiro achado, o autor que mais se destaca é Teece que apresenta três trabalhos na base de dados. Com relação ao número de documentos, Wright (371 citações) e Carayannis (65 citações) são os autores que mais contribuem com artigos sobre a temática de ecossistemas empreendedores na base de dados.

\begin{tabular}{lc|lc}
\hline \multicolumn{1}{c|}{ Autor } & Citações & \multicolumn{1}{c}{ Autor } & No Documentos $^{\mathbf{0}}$ \\
\hline Tecce, D. J. & 3543 & Wright, M. & 6 \\
Wright, M. & 371 & Carayannis, E. G. & 6 \\
Autio, E. & 326 & Nambisan, S. & 5 \\
Nambisan, S. & 322 & Audretch, D. B. & 5 \\
Mustar, P. & 310 & Feldman, M. & 5 \\
\hline
\end{tabular}

Figura 4 - Artigos com maior número de citação.

Fonte: elaboração própria. 
A partir dos resultados foi possível também identificar uma rede de citação que se forma entre os principais autores. A rede é apresentada na Figura 5. O tamanho da circunferência representa a interconexão com os outros autores da base em relação ao número de vezes que os autores se citam.

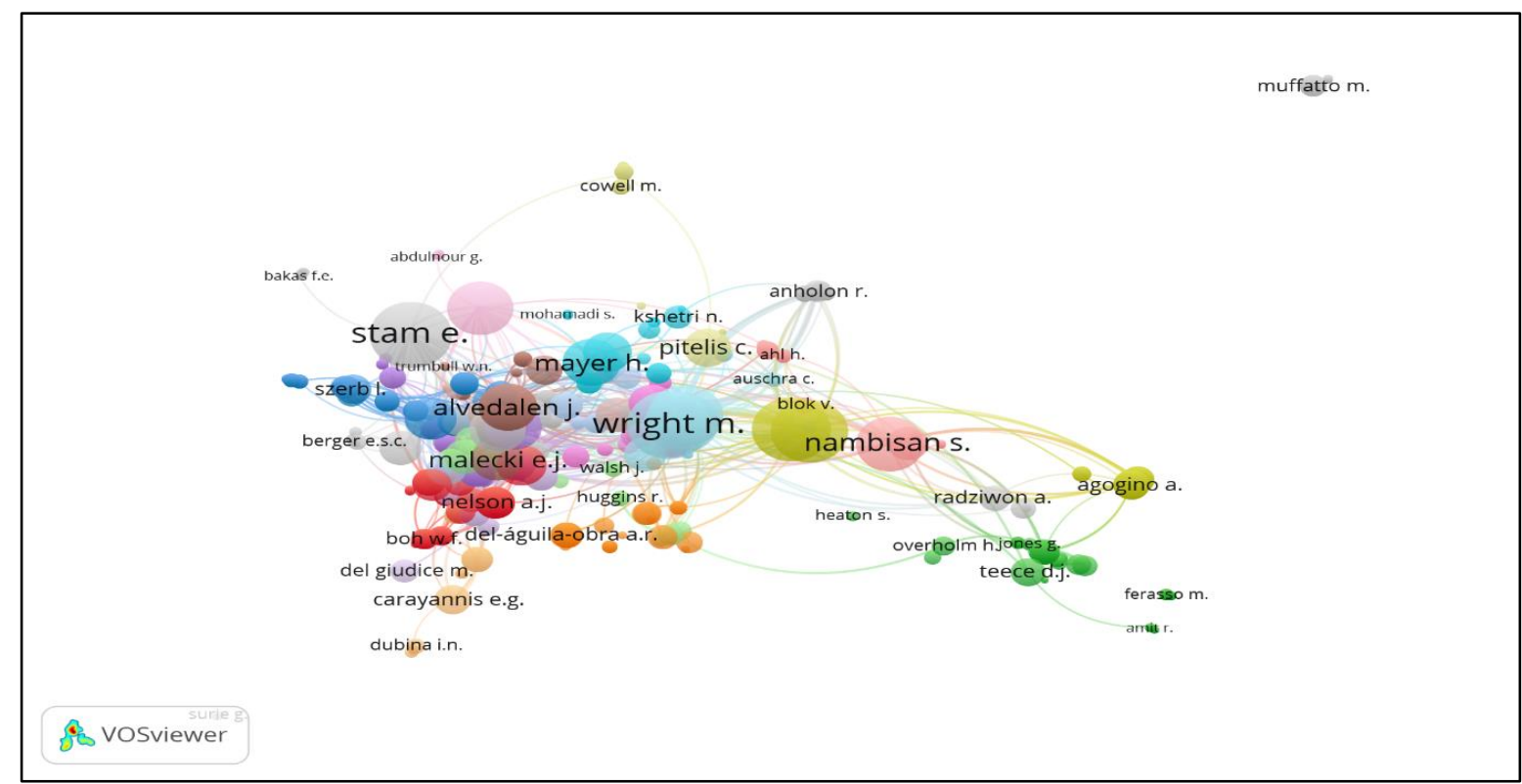

Figura 5 - Rede de autores mais citados.

Fonte: elaboração própria.

É possível observar que os autores com maior destaque na rede são: Wright (153 ligações), Stam (151 ligações), Siegel (137 ligações), Kenney (134 ligações) e Autio (129 ligações). Esses cinco autores representam $21 \%$ das interconexões entre autores que se citam na base de dados.

A Figura 6 demonstra a rede de coautoria na base de dados. No total há 869 diferentes autores, porém a rede da Figura 6 demonstra os 60 autores que possuem maior relacionamento de coautoria. Vale destacar que a base de dados possui sete diferentes clusters de coautoria sendo que dos cinco autores mais citados na base de dados, conforme destacado na Figura 4, quatro autores participam do mesmo cluster de coautoria (Wright, Autio, Nambisan e Mustar). Também é importante destacar que o autor Nambisan é um ponto focal da relação de coautoria com quatro diferentes clusters. 


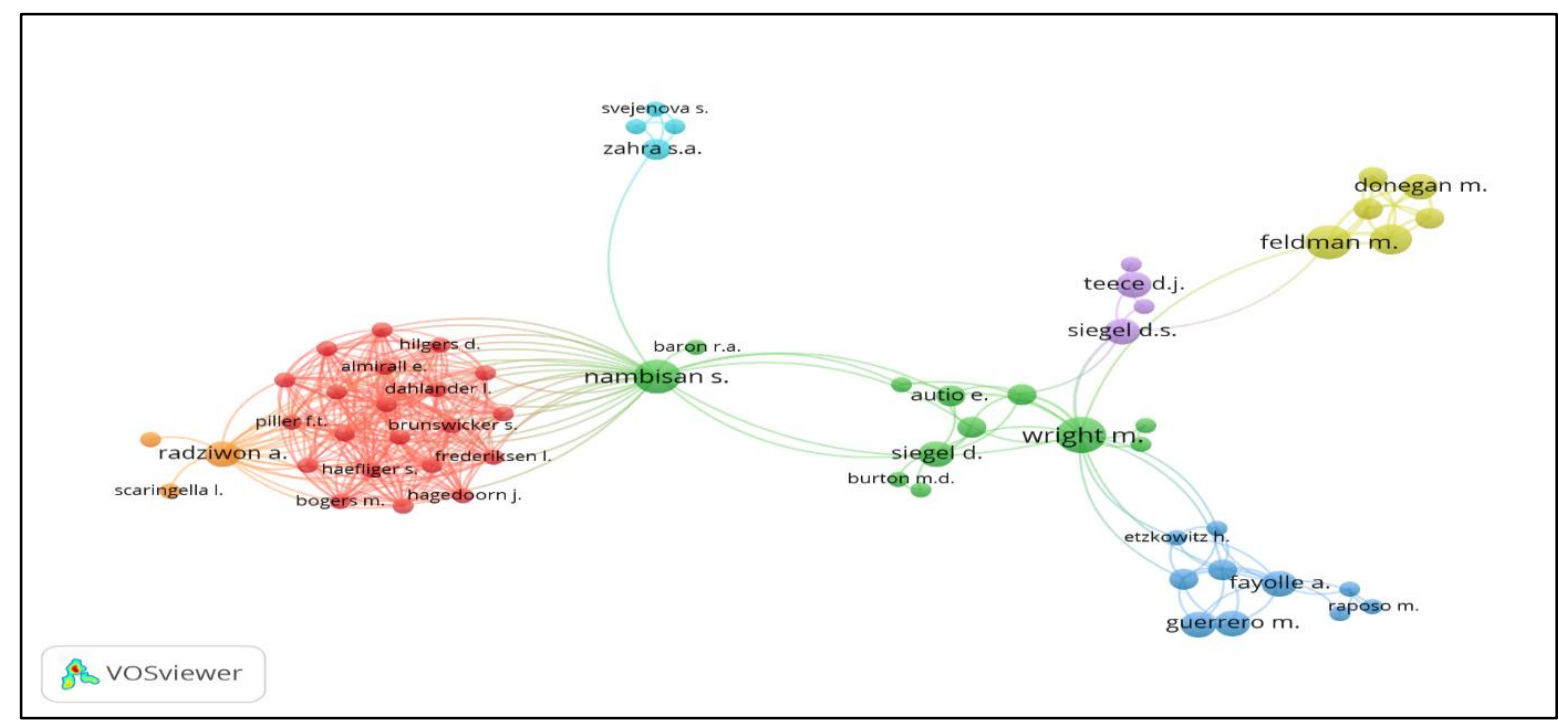

Figura 6 - Rede de coautoria.

Fonte: elaboração própria.

Outra análise que é possível realizar é a rede de coautoria entre países. No total há 57 países em que os autores estão filiados em instituições de pesquisa, porém a rede apresentada na Figura 7 é composta por 45 países que possuem relacionamento de coautoria. Conforme a Figura 7, os Estados Unidos é o país com maior conexão de coautoria com outros países (29 ligações), seguido pelo Reino Unido (25 ligações) e Alemanha (22 conexões). Os autores alocados em instituições brasileiras possuem relacionamento de coautoria com pesquisadores dos Estados Unidos, Reino Unido, Alemanha, China e Rússia.



Figura 7 - Rede de coautoria entre países.

Fonte: elaboração própria. 
O software VOSviewer ${ }^{\circledR}$ também permite analisar a rede de autores citados pelos documentos da base de dados. Essa rede é apresentada na Figura 8. A relação entre os autores é formada pelo número de vezes que os autores foram referenciados juntos pelo mesmo documento da base.

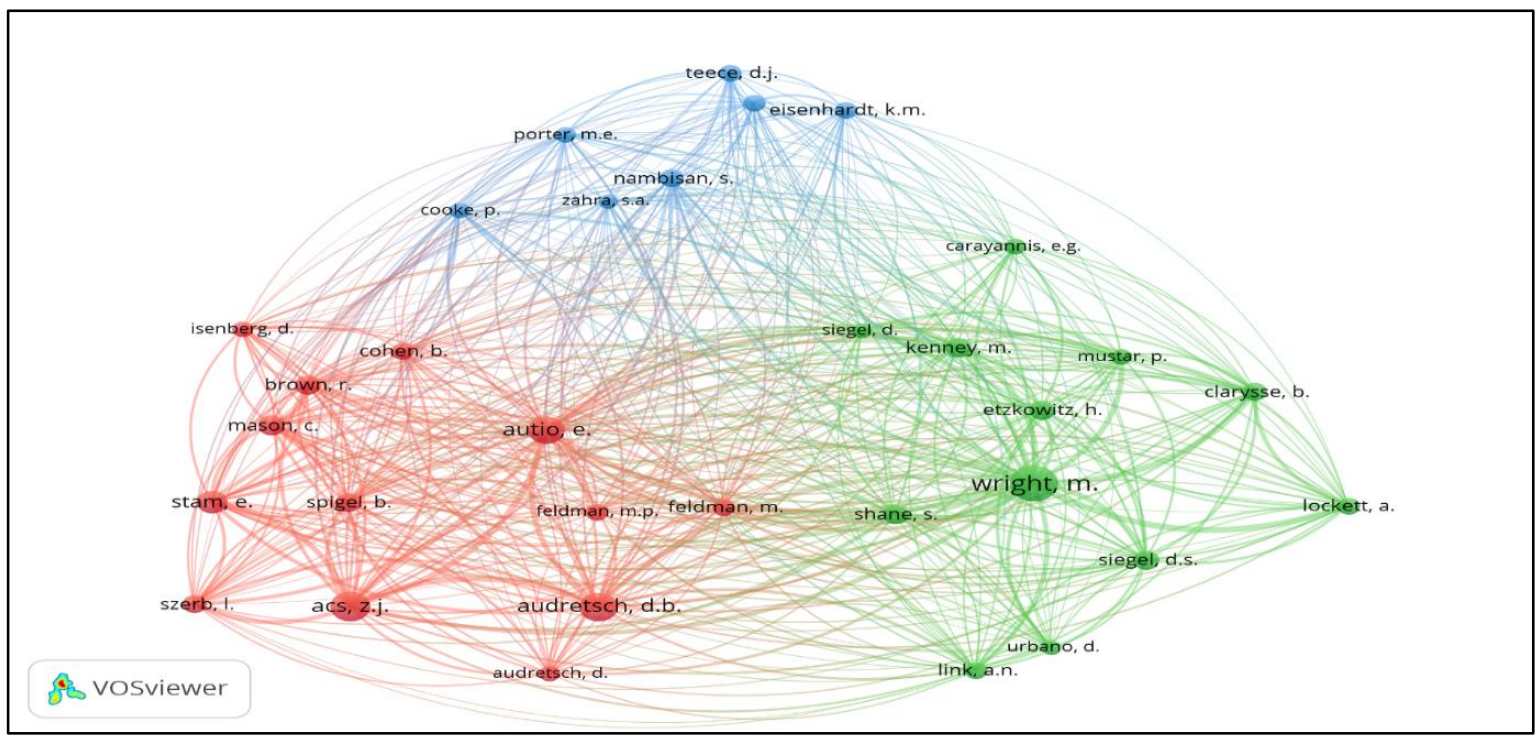

Figura 8 - Rede de autores referenciados.

Fonte: elaboração própria.

É interessante notar que há três clusters de referências que representam três embasamentos teóricos para a temática. O cluster azul evidencia autores que atuam em pesquisas sobre aspectos e definições estratégicas tais como Teece e Porter. No cluster verde há autores que se dedicam em estudos sobre empreendedorismo com uma ênfase maior no empreendedorismo acadêmico. Por fim, no cluster vermelho também há autores pesquisando temas relacionados ao empreendedorismo, porém com enfoque em ecossistema empreendedor.

A Figura 9 apresenta a rede de coocorrência entre palavras-chave utilizadas pelos autores da base de dados. No total os autores utilizaram 1.184 diferentes palavras-chave, porém para a formação da rede foram utilizadas as palavras-chave que possuem um mínimo de cinco ocorrências nos artigos da base de dados. Assim a rede apresentada na Figura 8 é formada com 44 palavras-chave. É possível visualizar que há uma maior ocorrência de tópicos estudados na temática de ecossistemas empreendedores tais como empreendedorismo universitário, startup, políticas públicas, transferência de tecnologia, venture capital dentre outros. 


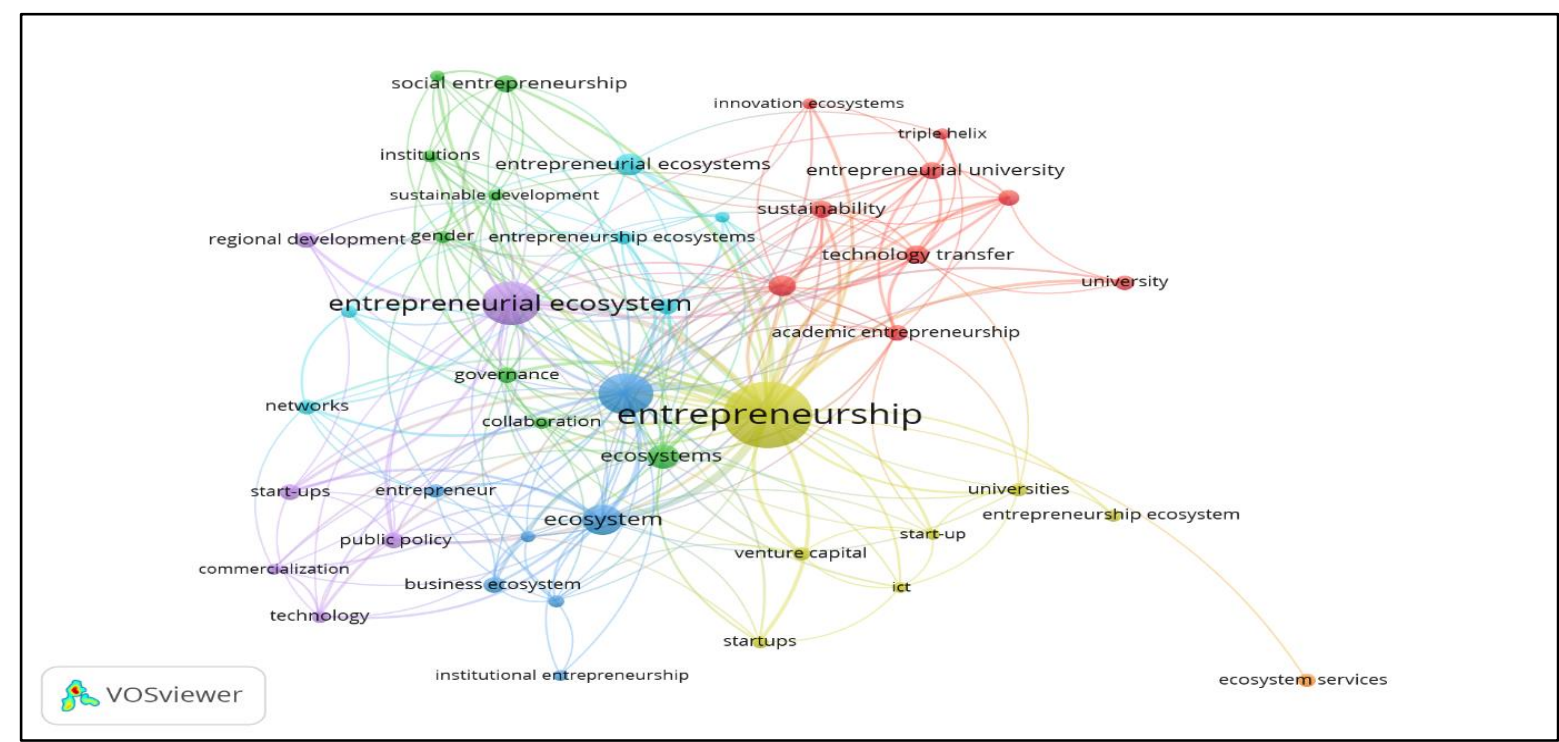

Figura 9 - Rede de palavras-chave mais utilizadas.

Fonte: elaboração própria.

A última análise realizada por meio do Software VOSviewer ${ }^{\circledR}$ foi a análise da rede de citações entre periódicos da base de dados. Essa rede é apresentada na Figura 10. No total a base de dados possui 174 periódicos, mas foi possível formar a rede de citação com 79 periódicos.

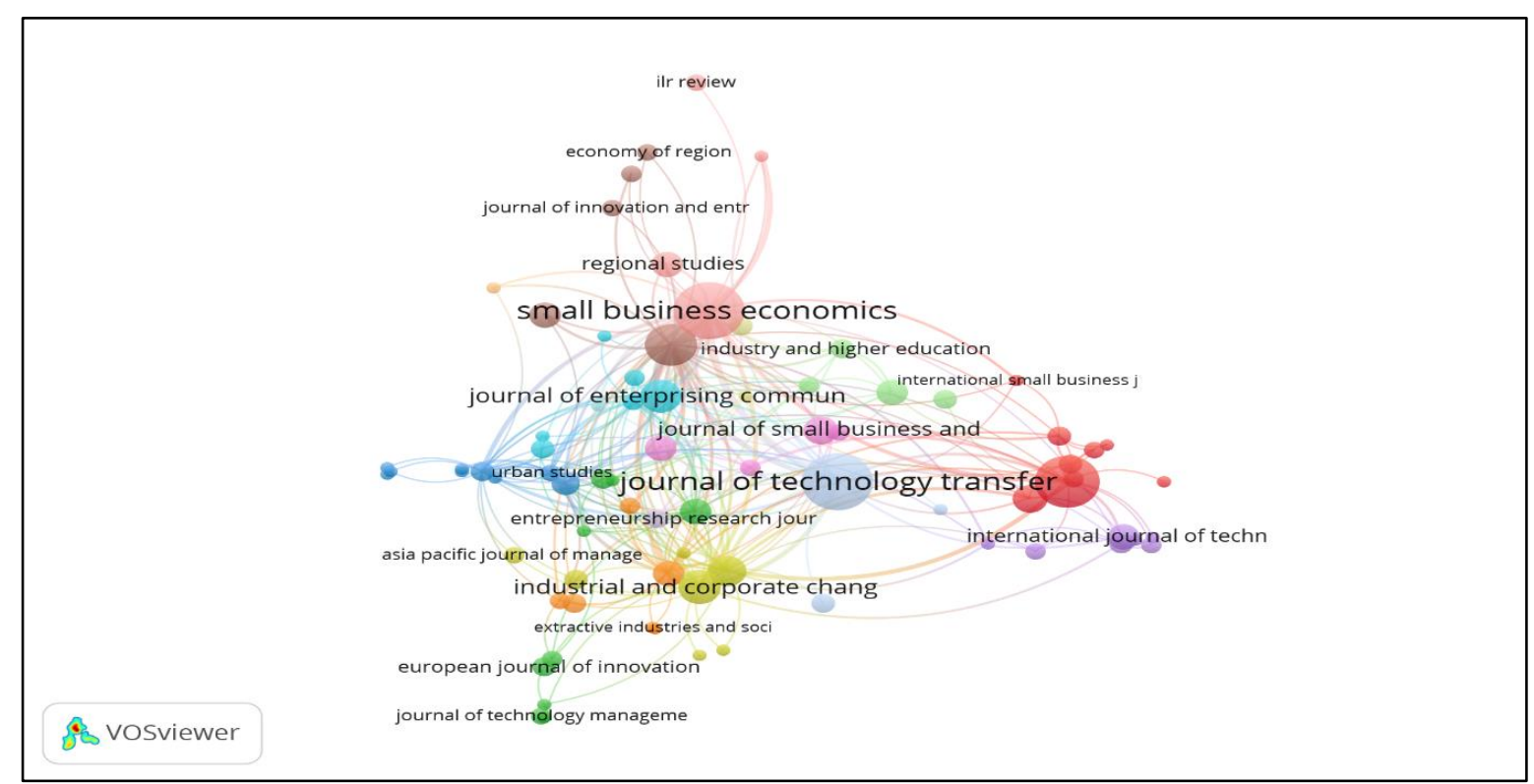

Figura 10-Rede de periódicos.

Fonte: elaboração própria. 
Por meio da Figura 10 é possível observar que há uma ampla de rede de citação entre os periódicos. O tamanho da circunferência representa a quantidade de documentos que o periódico contribui para a base de dados. Assim o periódico Small Business Economics (Fator de impacto em $2018=3.555)$ é o que mais contribui com artigos sobre a temática (24 documentos), periódico este que possui a maior rede de ligações com os outros periódicos da base (36 ligações). Na segunda posição vem o Journal of Technology Transfer (Fator de impacto em $2018=4.037)$ com 24 documentos e, em terceiro lugar o Technological Forecasting and Social Change (Fator de impacto em $2018=3.815$ ) com 20 documentos.

Com relação a quantidade de citações, o periódico Strategic Management Journal é o que possui maior quantidade de citações (3608 citações). Porém o resultado desse periódico é inflacionado pelo artigo de Teece (2007) que sozinho possui 3.543 citações, artigo que, conforme analisado anteriormente, não é uma pesquisa estritamente realizada sobre ecossistemas empreendedores. Portanto, para fins de análise, ao desconsiderar o artigo de Teece, o periódico que possui maior quantidade de citações é o Research Policy (476 citações) seguido do Small Business Economics (454 citações).

\section{$5 \quad$ Considerações Finais}

O presente estudo teve como objetivo principal apresentar o panorama das publicações de pesquisas científicas sobre ecossistema empreendedor* na base Scopus. Por meio da utilização do software VOSviewer ${ }^{\circledR}$, foi demonstrado os autores e artigos com maior número de publicações diante da temática pesquisada, principais redes de citação e cocitação, principais autores referenciados por obras da temática, principais eixos de pesquisas sobre o tema por meio das palavras-chave utilizadas e principais revistas científicas que publicam sobre o tema.

Portanto, a pesquisa atinge o objetivo proposto e traz contribuição teórica por demonstrar para a comunidade acadêmica que se interessa pelo assunto onde buscar informações e parcerias científicas para o avanço de pesquisas, além dos principais autores e temáticas da área de estudo.

Fato relevante deste estudo foi demonstrar que a pesquisa de Teece (2007) é seminal para o embasamento teórico da área, apesar de não ser uma pesquisa que aborda a temática de ecossistemas empreendedores. Também é relevante destacar que há uma predominância de estudos sobre empreendedorismo universitário na temática de ecossistemas empreendedores, tanto pela maior ocorrência de palavras-chave que se relacionam à essa temática, como também pelos principais autores referenciados pelos trabalhos de ecossistemas empreendedores.

Outras descobertas importantes deste estudo são: a importância dos periódicos Small Business Economics, Journal of Technology Transfer e Technological Forecasting and Social Change como principais disseminadores de artigos sobre a temática; os Estados Unidos da América e o Reino Unido como os países com maior ligações nas redes que desenvolvem estudos sobre essa temática. Vale notar o Brasil com cinco ligações de coautoria com autores de outros países.

Como limitação, a presente pesquisa destaca a utilização apenas da base de dados Scopus. Apesar da limitação, cabe destacar que a base Scopus possui um número significativo de periódicos com alto fator de impacto, o que garante a garante uma relevância para tal pesquisa.

Diante a limitação, são sugeridas as seguintes pesquisas futuras: pesquisa bibliométrica com demais bases de dados, tais como a Web of Science; a realização de outras análises 
permitidas com o uso do Software VOSviewer ${ }^{\circledR}$; análise qualitativa dos principais artigos da temática e a importância relativa de cada temática.

\section{Referências}

Acs, Z. J., Autio, E., \& Szerb, L. (2014). National systems of entrepreneurship: Measurement issues and policy implications. Research Policy, 43, 476-494.

Acs, Z. J., Stam, E., Audretsch, D. B., \& O'Connor, A. (2017). The lineages of the entrepreneurial ecosystem approach. Small Business Economics, 49(1), 1-10.

Anholon, R., Novaski, O., Pinto, J. S., \& Porto, G. S. (2016). Knowledge management in incubated companies: proposal of a model to enhance managerial skills. International Journal of Knowledge Management Studies, 7(1-2), 63-86.

Archambault, É., Campbell, D., Gingras, Y., \& Larivière, V. (2009). Comparing bibliometric statistics obtained from the Web of Science and Scopus. Journal of the American society for information science and technology, 60(7), 1320-1326.

Audretsch, D. B., \& Belitski, M. (2017). Entrepreneurial ecosystems in cities: establishing the framework conditions. The Journal of Technology Transfer, 42(5), 1030-1051.

Autio, E., \& Levie, J. (2017). Management of entrepreneurial ecosystems. The Wiley Handbook of Entrepreneurship. Chichester: John Wiley \& Sons, 423-449.

Cohen, B. (2006). Sustainable valley entrepreneurial ecosystems. Business Strategy and the Environment, 15(1), 1-14.

Igarashi, M., de Boer, L., \& Fet, A. M. (2013). What is required for greener supplier selection? A literature review and conceptual model development. Journal of Purchasing and Supply Management, 19(4), 247-263.

Isenberg, D. J. (2016). Applying the Ecosystem Metaphor to Entrepreneurship: Uses and abuses. The Antitrust Bulletin, 61(4), 564-573.

Kelly, T. and Firestone, R. (2016), "How tech hubs are helping to drive economic growth in Africa", World Development Report Background Paper.

Mack, E., \& Mayer, H. (2016). The evolutionary dynamics of entrepreneurial ecosystems. Urban Studies, 53(10), 2118-2133.

Maroufkhani, P., Wagner, R., \& Wan Ismail, W. K. (2018). Entrepreneurial ecosystems: a systematic review. Journal of Enterprising Communities: People and Places in the Global Economy, 12(4), 545-564.

Mas-Verdú, F., Ribeiro-Soriano, D., \& Roig-Tierno, N. (2015). Firm survival: The role of 
incubators and business characteristics. Journal of Business Research, 68(4), 793-796.

Morris, M. H., Neumeyer, X., \& Kuratko, D. F. (2015). A portfolio perspective on entrepreneurship and economic development. Small Business Economics, 45(4), 713-728.

Nylund, P. A., \& Cohen, B. (2017). Collision density: driving growth in urban entrepreneurial ecosystems. International entrepreneurship and management Journal, 13(3), 757-776.

Roundy, P. T., Bradshaw, M., \& Brockman, B. K. (2018). The emergence of entrepreneurial ecosystems: A complex adaptive systems approach. Journal of Business Research, 86, 1-10.

Seppelt, R., Dormann, C. F., Eppink, F. V., Lautenbach, S., \& Schmidt, S. (2011). A quantitative review of ecosystem service studies: Approaches, shortcomings and the road ahead. Journal of Applied Ecology, 48, 630-636.

Seuring, S., \& Müller, M. (2008). From a literature review to a conceptual framework for sustainable supply chain management. Journal of cleaner production, 16(15), 1699-1710.

Singer, S., Amoros, J.E. and Moska, D. (2015) The Global Entrepreneurship Monitor, The 2014 Global Report.

Shepard, J. M. (2013). Small business incubators in the USA: a historical review and preliminary research findings. Journal of Knowledge-based Innovation in China, 5(3), 213233.

Spigel, B. (2017). The Relational Organization of Entrepreneurial Ecosystems. Entrepreneurship Theory and Practice, 41(1), 49-72.

Stam, E. (2015). Entrepreneurial ecosystems and regional policy: A sympathetic critique. European Planning Studies, 23, 1759-1769.

Tranfield, D., Denyer, D., \& Smart, P. (2003). Towards a methodology for developing evidence-informed management knowledge by means of systematic review. British journal of management, 14(3), 207-222.

Teece, D. J. (2007). Explicating dynamic capabilities: the nature and microfoundations of (sustainable) enterprise performance. Strategic management journal, 28(13), 1319-1350.

Yan, Y., \& Guan, J. (2019). Entrepreneurial ecosystem, entrepreneurial rate and innovation: the moderating role of internet attention. International Entrepreneurship and Management Journal, 15(2), 625-650. 